NASA/TM-2012-217722

\title{
A Comparison of Candidate Seal Designs for Future Docking Systems
}

Patrick H. Dunlap, Jr. and Bruce M. Steinetz

Glenn Research Center, Cleveland, Ohio 


\section{NASA STI Program . . . in Profile}

Since its founding, NASA has been dedicated to the advancement of aeronautics and space science. The NASA Scientific and Technical Information (STI) program plays a key part in helping NASA maintain this important role.

The NASA STI Program operates under the auspices of the Agency Chief Information Officer. It collects, organizes, provides for archiving, and disseminates NASA's STI. The NASA STI program provides access to the NASA Aeronautics and Space Database and its public interface, the NASA Technical Reports Server, thus providing one of the largest collections of aeronautical and space science STI in the world. Results are published in both non-NASA channels and by NASA in the NASA STI Report Series, which includes the following report types:

- TECHNICAL PUBLICATION. Reports of completed research or a major significant phase of research that present the results of NASA programs and include extensive data or theoretical analysis. Includes compilations of significant scientific and technical data and information deemed to be of continuing reference value. NASA counterpart of peer-reviewed formal professional papers but has less stringent limitations on manuscript length and extent of graphic presentations.

- TECHNICAL MEMORANDUM. Scientific and technical findings that are preliminary or of specialized interest, e.g., quick release reports, working papers, and bibliographies that contain minimal annotation. Does not contain extensive analysis.

- CONTRACTOR REPORT. Scientific and technical findings by NASA-sponsored contractors and grantees.
- CONFERENCE PUBLICATION. Collected papers from scientific and technical conferences, symposia, seminars, or other meetings sponsored or cosponsored by NASA.

- SPECIAL PUBLICATION. Scientific, technical, or historical information from NASA programs, projects, and missions, often concerned with subjects having substantial public interest.

- TECHNICAL TRANSLATION. Englishlanguage translations of foreign scientific and technical material pertinent to NASA's mission.

Specialized services also include creating custom thesauri, building customized databases, organizing and publishing research results.

For more information about the NASA STI program, see the following:

- Access the NASA STI program home page at http://www.sti.nasa.gov

- E-mail your question to help@sti.nasa.gov

- Fax your question to the NASA STI Information Desk at 443-757-5803

- Phone the NASA STI Information Desk at 443-757-5802

- Write to: STI Information Desk NASA Center for AeroSpace Information 7115 Standard Drive Hanover, MD 21076-1320 
NASA/TM-2012-217722

\section{A Comparison of Candidate Seal Designs for Future Docking Systems}

Patrick H. Dunlap, Jr. and Bruce M. Steinetz

Glenn Research Center, Cleveland, Ohio

Prepared for the

48th Joint Propulsion Conference and Exhibit

cosponsored by the AIAA, ASME, SAE, and ASEE

Atlanta, Georgia, July 30-August 1, 2012

National Aeronautics and

Space Administration

Glenn Research Center

Cleveland, Ohio 44135 


\section{Acknowledgments}

The authors would like to thank the International Low Impact Docking System team from NASA Johnson Space Center for their support on this project. The authors would also like to acknowledge Parker Hannifin Corporation's Composite Sealing Systems Division (San Diego, CA) for fabricating all of the seal test specimens that were evaluated in this study. Portions of the works that were referenced in this study were supported by NASA contract number NNC08CA35C.

Trade names and trademarks are used in this report for identification only. Their usage does not constitute an official endorsement, either expressed or implied, by the National Aeronautics and Space Administration.

Level of Review: This material has been technically reviewed by technical management.

Available from

NASA Center for Aerospace Information 7115 Standard Drive

Hanover, MD 21076-1320
National Technical Information Service 5301 Shawnee Road Alexandria, VA 22312

Available electronically at http://www.sti.nasa.gov 


\title{
A Comparison of Candidate Seal Designs for Future Docking Systems
}

\author{
Patrick H. Dunlap, Jr. and Bruce M. Steinetz \\ National Aeronautics and Space Administration \\ Glenn Research Center \\ Cleveland, Ohio 44135
}

\begin{abstract}
NASA is developing a new docking system to support future space exploration missions to low Earth orbit, the Moon, and other destinations. A key component of this system is the seal at the main docking interface which inhibits the loss of cabin air once docking is complete. Depending on the mission, the seal must be able to dock in either a seal-on-flange or seal-on-seal configuration. Seal-on-flange mating would occur when a docking system equipped with a seal docks to a system with a flat metal flange. This would occur when a vehicle docks to a node on the International Space Station. Seal-on-seal mating would occur when two docking systems equipped with seals dock to each other. Two types of seal designs were identified for this application: Gask-O-seals and multi-piece seals. Both types of seals had a pair of seal bulbs to satisfy the redundancy requirement. A series of performance assessments and comparisons were made between the candidate seal designs indicating that they meet the requirements for leak rate and compression and adhesion loads under a range of operating conditions. Other design factors such as part count, integration into the docking system tunnel, seal-on-seal mating, and cost were also considered leading to the selection of the multi-piece seal design for the new docking system. The results of this study can be used by designers of future docking systems and other habitable volumes to select the seal design best-suited for their particular application.
\end{abstract}

\section{Nomenclature}

$\begin{array}{ll}\text { AO } & \text { atomic oxygen } \\ \text { CBM } & \text { Common Berthing Mechanism } \\ \text { GRC } & \text { Glenn Research Center } \\ \text { ISS } & \text { International Space Station } \\ \text { kip } & \text { one thousand } \mathrm{lb}_{\mathrm{f}} \\ \text { LEO } & \text { low Earth orbit } \\ \text { SOF } & \text { seal-on-flange } \\ \text { SOS } & \text { seal-on-seal }\end{array}$

\section{Introduction}

NASA is developing a new docking system to enable in-space mating of vehicles and structures for missions to low Earth orbit (LEO) and deep space. A key component of this system is the seal at the main docking interface on the top of the docking system tunnel (Figure 1). This seal is relatively large with a diameter on the order of 50 in. $(127 \mathrm{~cm})$ and is compressed during the docking process. After docking, the seal must exhibit extremely low leak rates for extended missions to the International Space Station (ISS) or the Moon, for example. 


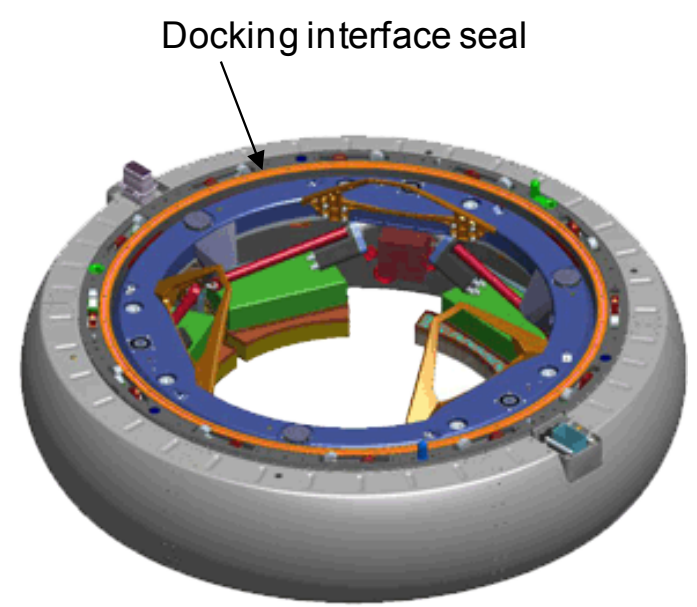

Figure 1.-Docking interface seal location.

The design for the docking interface seals has evolved with the docking system, so this trade study was conducted to ensure that the best seal design would be used for the most recent iteration of the docking system. The goals for this study were to:

- Identify candidate seal designs for the docking system,

- Assess their performance against a baseline set of requirements, and

- Summarize the key advantages and disadvantages of each candidate design for this application.

\section{Key Requirements}

The key seal requirements considered in this study are summarized in this section. Additional details on requirements for docking system seals can be found in the papers by Dunlap et al. (Refs. 1 and 2).

\section{Leak Rate}

The most important function for the docking interface seal is to minimize leakage through the interface between two mated systems. Leak rates on the order of $2.5 \times 10^{-3} \mathrm{lb}_{\mathrm{m}}$ of air $\left(\mathrm{lb}_{\mathrm{m} \text {,air }}\right)$ per day $\left(1.1 \times 10^{-3} \mathrm{~kg} /\right.$ day $)$ are required at this interface to ensure that the astronauts have sufficient breathable air during extended-duration missions.

\section{Compression Loads}

When two vehicles or structures mate during a mission, the seals at the interface between them will generate loads as they are compressed. To stay within the capabilities of the mechanisms that join the two vehicles together (e.g., latches), the seal loads must stay below prescribed limits so that full closure can occur without overloading the mechanisms (Figure 2). Seal compression loads per linear inch of seal must be less than approximately $70 \mathrm{lb}_{\mathrm{f}}$ per in. $(122 \mathrm{~N}$ per $\mathrm{cm})$ to ensure that the total compression load for a pair of 50 in.-diameter seals is less than 22 kip. 


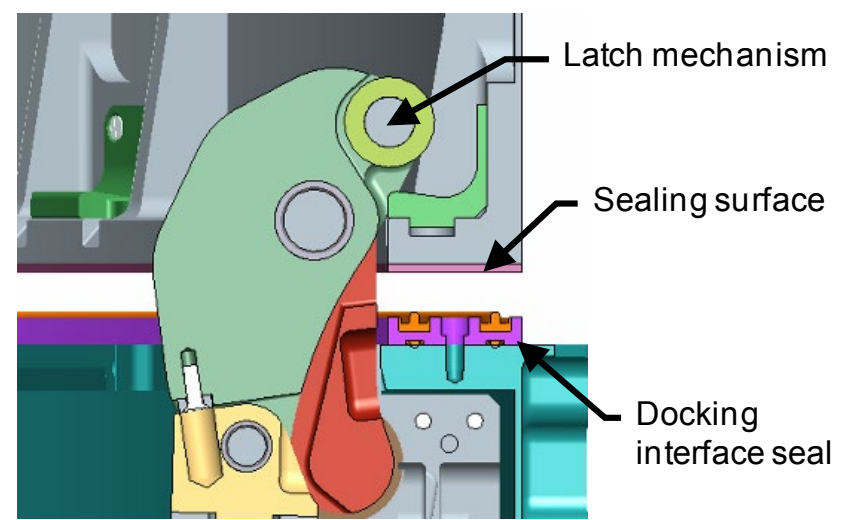

(a)

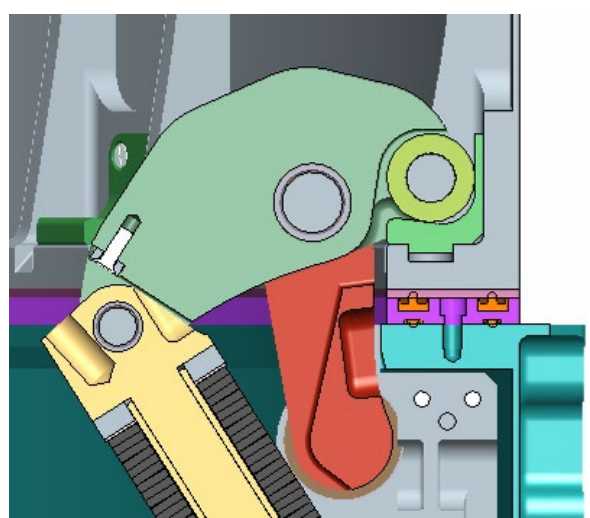

(b)

Figure 2.--Representative views of docking interface (a) just before latch mechanisms engage and (b) after latches have fully compressed the seal.
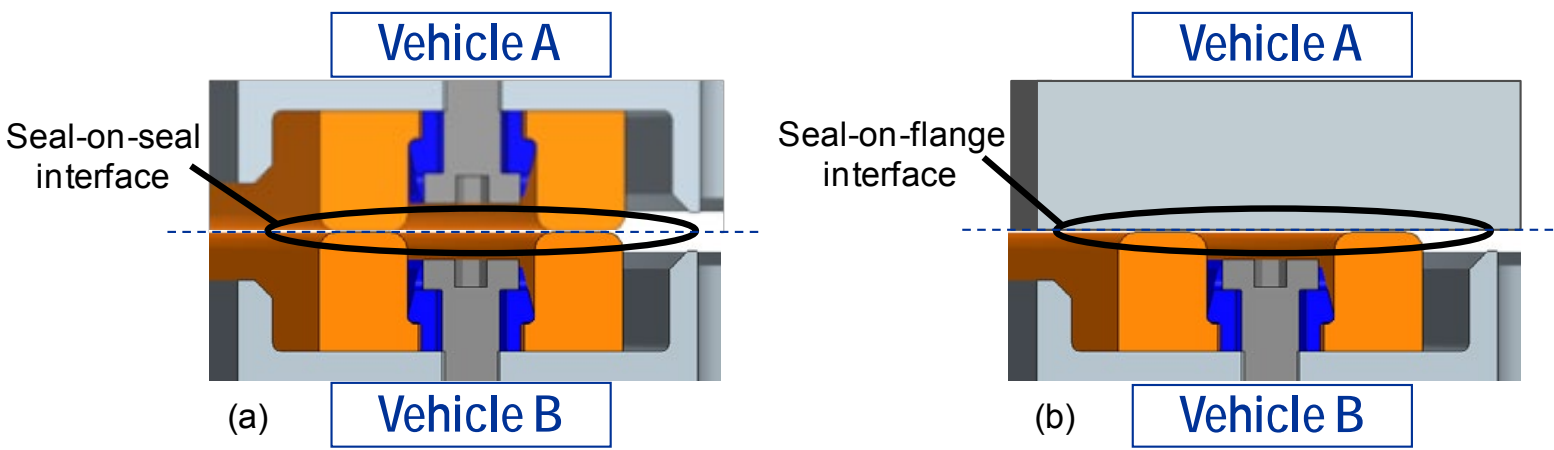

Figure 3.-Cross sections through the interface between two mated systems showing (a) seal-on-seal mating and (b) seal-on-flange mating.

\section{Adhesion Loads}

The seals must also exhibit very low adhesion forces when two mated systems separate. High seal adhesion loads could potentially restrict the ability of the systems to separate and perhaps even prevent the vehicles from undocking. High adhesion loads could also damage the seals during undocking, thereby preventing the vehicle from re-docking in the future. To prevent this from occurring, full-scale seal adhesion loads of $200 \mathrm{lb}_{\mathrm{f}}$ or less are desired.

\section{Mating Configuration}

Docking can occur in an androgynous seal-on-seal configuration in which both sides of the interface have seals installed or in a seal-on-flange configuration with a seal on one side of the interface and a flat, smooth metal flange on the other. Seal-on-flange mating would occur when a vehicle with a seal installed on its docking system docks to a node on the ISS with a flat metal flange. Seal-on-seal mating would occur when two vehicles equipped with seals on their docking systems dock to each other. Figure 3 illustrates both of these configurations for a candidate seal design. 


\section{Use of Redundant Sealing Features}

Manned space systems require that all seal locations with diameters larger than 6.0 in. $(15 \mathrm{~cm})$ have a minimum of two seals for redundancy. Because future docking system seals will likely have diameters on the order of 50 in. $(127 \mathrm{~cm})$, redundant sealing features must be implemented. This allows the sealed interface to be single fault tolerant wherein it can still satisfy the leak rate requirement even if one of the seals has been compromised.

\section{Engagement Conditions}

Under certain conditions, the seals may not be fully compressed when they are mated resulting in metal-to-metal joint separation (or "gapping") at the sealing interface. Periodic gapping can also occur between latching mechanisms due to flange deflections around the perimeter of the docking tunnel. Either situation can occur under steady state or transient conditions, although these situations are more likely under transient conditions when dynamic loads are applied across the interface.

The sealing surfaces on each system will likely not be perfectly radially aligned during mating due to several factors:

- Manufacturing and assembly tolerances of the docking interface components, including the seals

- Differences in tunnel temperatures between mating vehicles

Radial misalignments do not typically affect seal-on-flange mating because the seal on one side of the interface is able to form an effective seal when it is compressed anywhere against the flat metal flange. However, seal-on-seal mating can be greatly affected by radial misalignments. When tolerance stackups are combined with differences in mating tunnel temperatures, radial offsets on the order of 0.125 in. $(0.315 \mathrm{~cm})$ between mating seal bulb centerlines can occur. Under these conditions, the amount of seal-toseal contact is reduced resulting in less effective sealing and potentially higher leak rates.

\section{Candidate Seal Designs}

Two types of seals were evaluated in this study: a composite Gask-O-seal design produced by Parker Hannifin Corporation (San Diego, CA) and a multi-piece seal design co-invented by The University of Akron (Akron, $\mathrm{OH}$ ) and NASA Glenn Research Center (GRC).

\section{Gask-O-Seals}

Gask-O-seals are formed by molding silicone elastomer seals directly into the grooves of a metallic (e.g., aluminum) retainer to form a single-piece seal assembly. Each seal features a bulb in the center of the groove with voids on either side to allow the bulb to spread out when it is compressed. The seal bulb is sized to prevent the incompressible rubber from completely filling the groove when it is fully compressed. This design has space flight experience and has been used as a static seal in multiple locations on the ISS including seals for the Common Berthing Mechanism (CBM) (Ref. 3), windows, hatches, and electrical connectors.

As illustrated in Figure 4, the Gask-O-seal designs evaluated in this study have dual bulbs on both the "front" and "back" sides of the retainer to meet the redundancy requirement. The seal bulbs on the front side are compressed during docking, and those on the back side are compressed when the seal assembly is installed on the docking system tunnel. In the design shown in Figure 4, the cross sections of the two front seal bulbs are identical. The back seal bulbs are also identical, although they are smaller than the front seals. However, the sizes and shapes of the seal bulbs could all be the same and can be tailored to meet the needs of a specific application. 


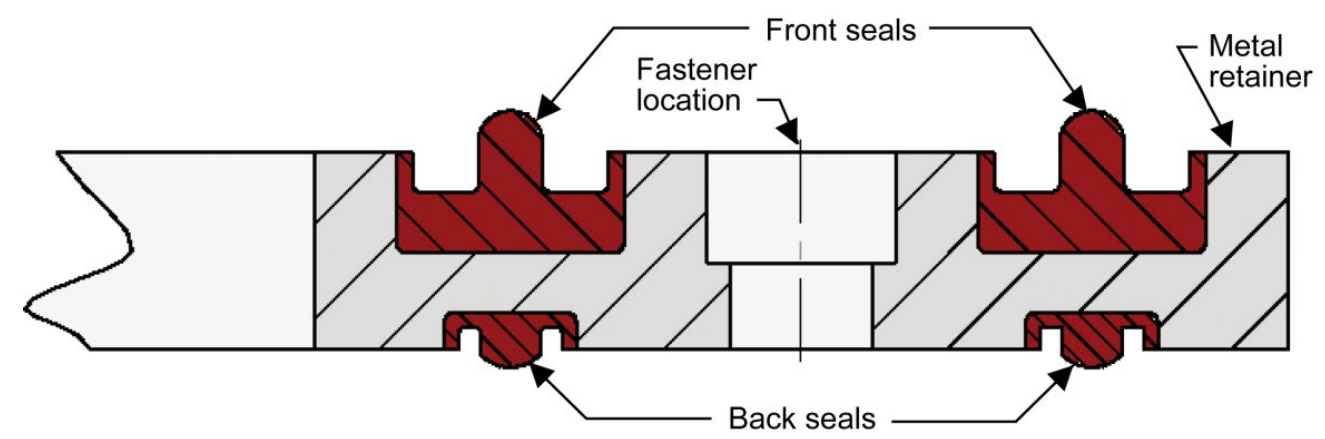

Figure 4.-Cross section through Gask-O-seal showing silicone seals molded into grooves on front and back surfaces of metal retainer.

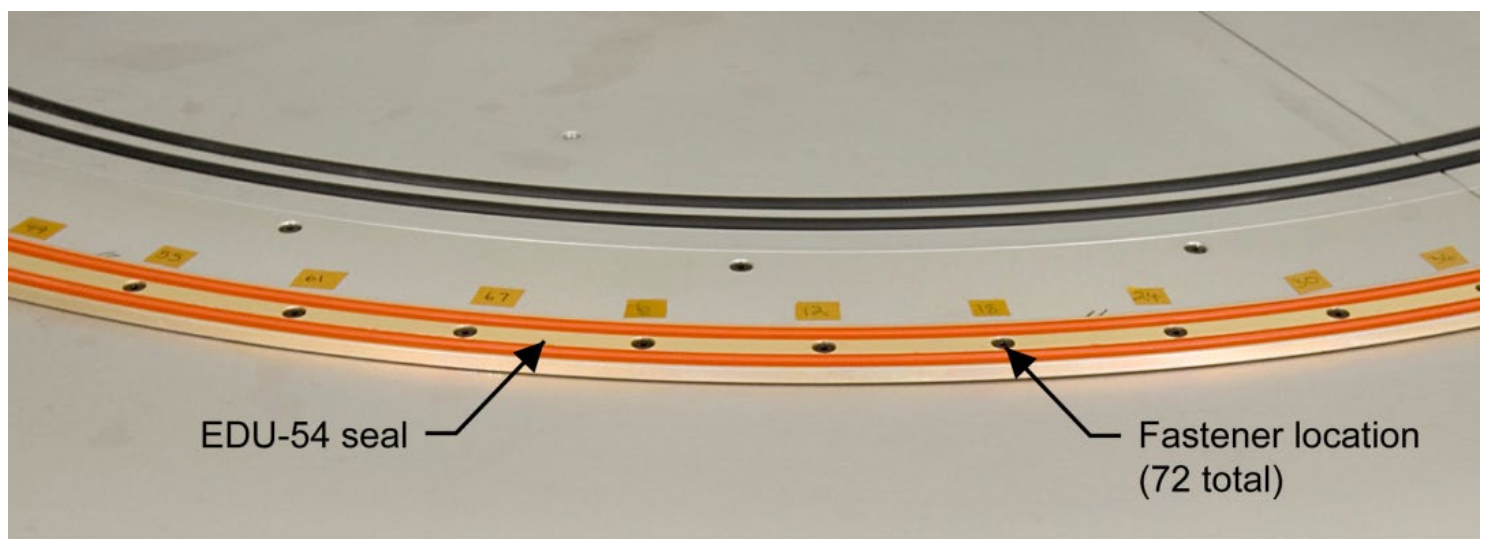

Figure 5.-Photograph of 54-in. diameter (EDU-54) Gask-O-seal installed in test apparatus showing dual front seal bulbs and fastener holes.

This seal assembly was designed to be installed directly on the top of a docking system tunnel without requiring a separate groove or flange. Alignment pin holes in the retainer (not shown) are used to align the axes of the seal and the docking system tunnel during seal installation, and fasteners are used to attach the seal assembly to the top of the tunnel. Figure 5 shows a close up view of a 54 -in. diameter seal installed in a leak test apparatus at NASA GRC.

Several different Gask-O-seal designs were evaluated in this study: EDU54, EDU58-1, EDU58-2, EDU58-3, and EDU58-4. The cross sections of the seal bulbs for each design were different, but the details are proprietary and can only be described in general terms. For the EDU54 seals, the "free heights" of the seal bulbs above the surrounding metal retainer for the front and back seals were nominally 0.040 in. $(1.0 \mathrm{~mm})$ and 0.023 in. $(0.58 \mathrm{~mm})$, respectively (Ref. 4). The four EDU58 seal designs had different bulb cross sections than those for the EDU54 seals. All four EDU58 designs were similar to each other except for the heights of their front side seal bulbs. The EDU58-1 seals had the shortest seal bulbs, and those for the EDU58-2, EDU58-3, and EDU58-4 were 11, 20, and 31 percent taller than the EDU58-1 design, respectively (Ref. 5). 


\section{Multi-Piece Seal Design}

The multi-piece seal design consists of an elastomer element with two seal bulbs connected by a web and a separate metal retainer with periodic bosses that pass through openings in the web (Figure 6 and Figure 7). Whereas the Gask-O-seal would be installed directly on the top of a docking system tunnel, the multi-piece seal would be installed in a groove on the top of a tunnel. A series of fasteners secures the seal assembly to the base of the seal groove.

Like the Gask-O-seal design, the elastomer seal element is molded out of silicone and has two seal bulbs to satisfy the redundancy requirement. However, unlike the Gask-O-seal, the metal retainer is a separate element (or elements for a multi-segment retainer), and the elastomer seal bulbs are not molded directly into it. The retainer in this design anchors the elastomer seal element to the tunnel and locates and centers the seal assembly in the tunnel groove.

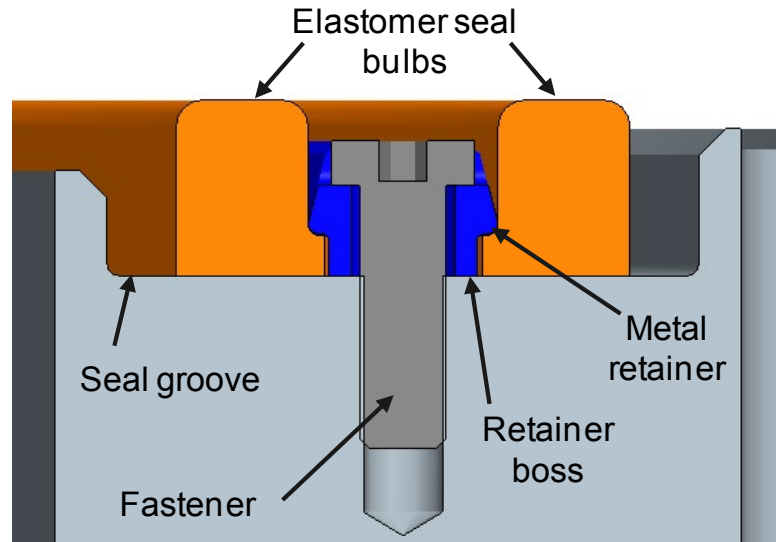

(a)

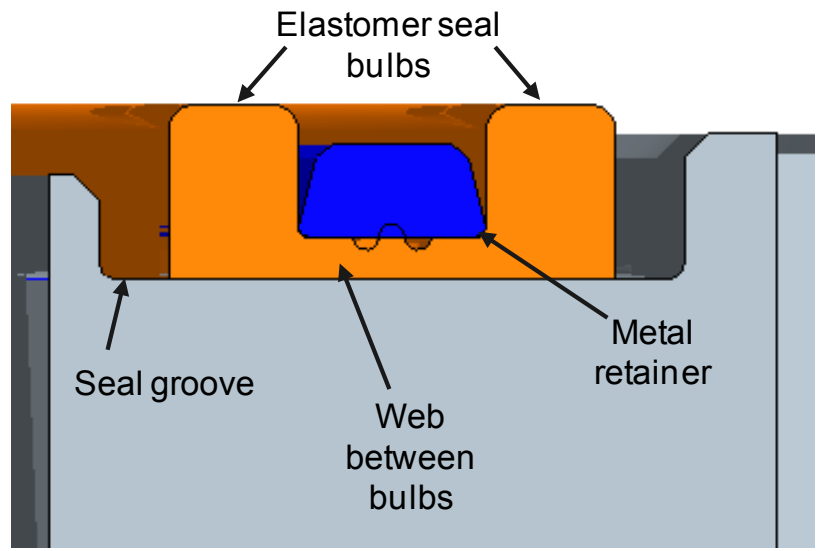

(b)

Figure 6.-Cross section through multi-piece seal assembly (a) at fastener location and (b) at location between fasteners.

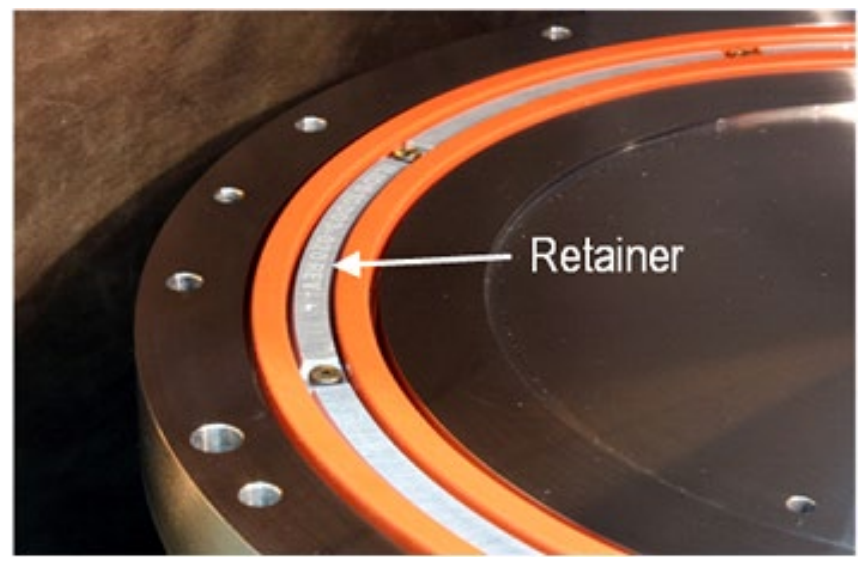

Figure 7.--Photograph of subscale multi-piece seal installed in groove in test apparatus. 


\section{Seal Materials}

All performance comparisons made in this study are for seals made of S0383-70, a 70 durometer silicone material. This material has been used in a variety of space flight applications including those mentioned previously for Gask-O-seals and has been shown to meet outgassing requirements when properly cured (Ref. 6). Evaluating seals made of the same material allows comparisons to be made solely on the basis of design differences.

Although silicone seals are well-suited for space flight applications, their adhesion loads have been shown to be quite high if left untreated (Refs. 7 to 10). In many cases, these loads are beyond the push-off capabilities of planned docking system separation mechanisms. However, these same studies also showed that pre-treatment of the seals with low doses (e.g., $1 \times 10^{20}$ atoms $/ \mathrm{cm}^{2}$ ) of atomic oxygen (AO) drastically reduced seal adhesion loads without adversely affecting seal compression loads or leak rates. Banks et al. (Refs. 11 and 12) showed that AO passivates silicone elastomers and significantly reduces the adhesion of the sealing surfaces. The current study includes comparisons of both families of seal designs (Gask-Oseals and multi-piece seals) with and without AO pretreatment.

\section{Performance Assessments and Comparisons}

The performance of the EDU54 Gask-O-seal design has been documented by Smith et al. (Ref. 4) and Wasowski et al., (Ref. 6) while Garafolo et al. (Refs. 9 and 13) and Bastrzyk et al. (Ref. 5) tested the various EDU58 designs. Multi-piece seal performance testing has been reported on by Oravec et al. (Refs. 14 and 15) and Dunlap et al. (Ref. 16). The results of these works are compared to each other and to the design requirements in the sections below.

\section{Leak Rate}

\section{Effects of Mating Configuration}

Figure 8 compares the leak rates for EDU54 (Refs. 4 and 6) and EDU58-1 (Ref. 9) Gask-O-seals and multi-piece seals (Ref. 16) across a range of temperatures from -58 to $122^{\circ} \mathrm{F}\left(-50\right.$ to $50{ }^{\circ} \mathrm{C}$ ) when fully compressed in a seal-on-flange configuration. The values plotted in this figure are extrapolated leak rates for 50-in. diameter versions of each seal design based on leakage measured for seals of various diameters. This was done so that fair comparisons could be made between the different designs.

For each seal design, the leak rate increased as the test temperature increased. This has been attributed to an increase in the permeability of the elastomer as the temperature rises (Ref. 13). An increase in seal leakage was also observed for the EDU58-1 seals after they were pretreated with AO. However, in all cases, the projected leak rates were well below the leakage threshold of $2.5 \times 10^{-3} \mathrm{lb}_{\mathrm{m} \text {,air }} /$ day.

Leak rates in the seal-on-seal configuration have only been documented for the EDU54 Gask-O-seals. Smith et al. (Ref. 4) performed a series of tests on the EDU54 seals at room temperature and measured leak rates on the order of $1 \times 10^{-6} \mathrm{lb}_{\mathrm{m} \text {,air }}$ /in./day for fully compressed seals. This corresponds to a leak rate of approximately $1.6 \times 10^{-4} \mathrm{lb}_{\mathrm{m} \text {,air }} /$ day for a $50 \mathrm{in}$. diameter seal. Although this is a higher leak rate than what was projected for the same seal in a seal-on-flange configuration $\left(3.7\right.$ to $7.7 \times 10^{-5} 1 \mathrm{~b}_{\mathrm{m} \text {,air }} /$ day $)$, it is still an order of magnitude below the leakage threshold.

\section{Effects of Incomplete Compression}

Several studies have evaluated the ability for the candidate seal designs to meet the leak rate requirement under various levels of compression. Smith et al. (Ref. 4) showed that the EDU54 seal design formed an effective seal at room temperature when the mating sealing surfaces were gapped by as much as $0.035 \mathrm{in}$. in a seal-on-flange configuration and up to $0.075 \mathrm{in}$. when mated seal-on-seal. Garafolo et al. (Ref. 13) showed that the leak rate for the EDU58-3 seal design increased as the amount of compression 


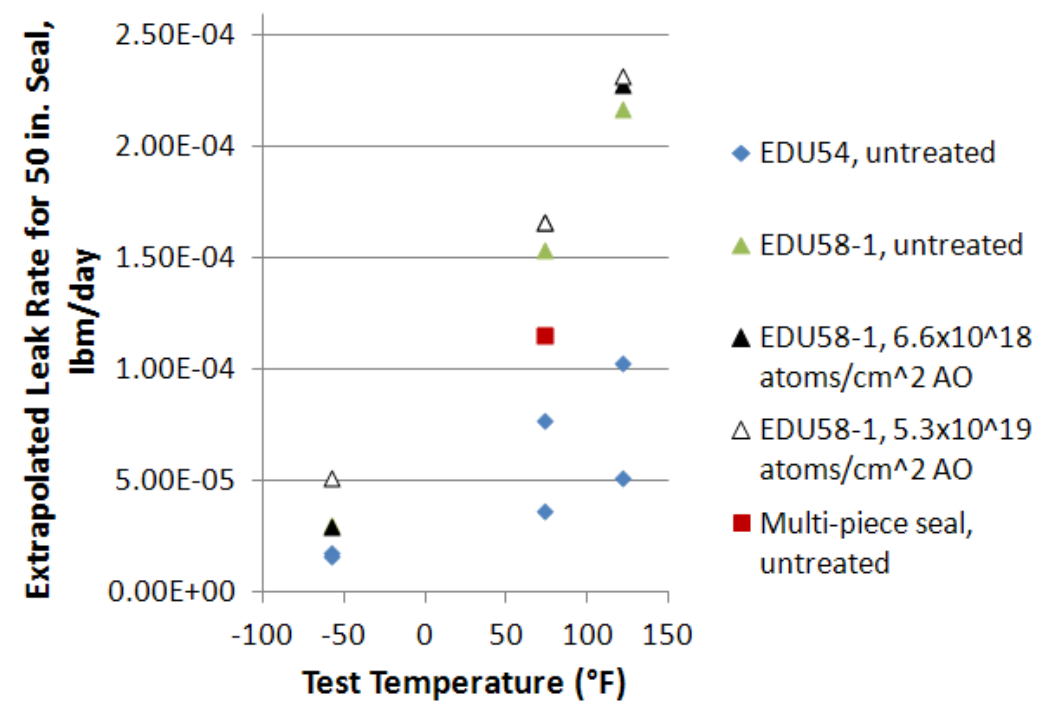

Figure 8.-Extrapolated leak rates for 50 in. diameter versions of candidate seal designs based on leakage measured for fully compressed seals in the seal-on-flange mating configuration across a range of temperatures.

on the seal was reduced for seal-on-flange mating. However, even at the warmest test temperature of $122^{\circ} \mathrm{F}\left(50^{\circ} \mathrm{C}\right)$ and only 48 percent closure, the seal still satisfied the leak rate requirement by an order of magnitude. Based on the results of these tests, both the EDU54 and EDU58-3 seal designs have been shown to be tolerant of incomplete compression and able to satisfy the leak rate requirement under those conditions.

\section{Effects of Radial Misalignment}

Radial misalignment is only an issue for the candidate seal designs when they are mated in the sealon-seal configuration. As noted earlier, only Smith et al. (Ref. 4) has published results for any of the candidate seal designs in that configuration. In that study, the leak rate for the EDU54 seal was shown to slowly increase as the amount of radial misalignment was increased to a value of $0.120 \mathrm{in}$. However, the seal still met the leak rate requirement under those conditions. The leak rate exceeded the leakage threshold when the seal test specimens were misaligned by 0.150 in.

\section{Compression Loads}

All of the seal designs considered in this study met the compression load requirement under the conditions in which they were evaluated. Figure 9 plots compression loads measured for EDU54 (Ref. 4) and EDU58-1 (Ref. 9) Gask-O-seals and multi-piece seals (Ref. 14) in the seal-on-flange mating configuration across a range of temperatures from -58 to $167^{\circ} \mathrm{F}\left(-50\right.$ to $\left.75^{\circ} \mathrm{C}\right)$. The values plotted in this figure represent the force required to compress the front seal bulbs for the Gask-O-seals and the entire seal bulbs for the multi-piece seals. These loads were measured from the first load cycle for the EDU54 seals and multi-piece seals and are the average of 20 load cycles for the EDU58-1 seals. 


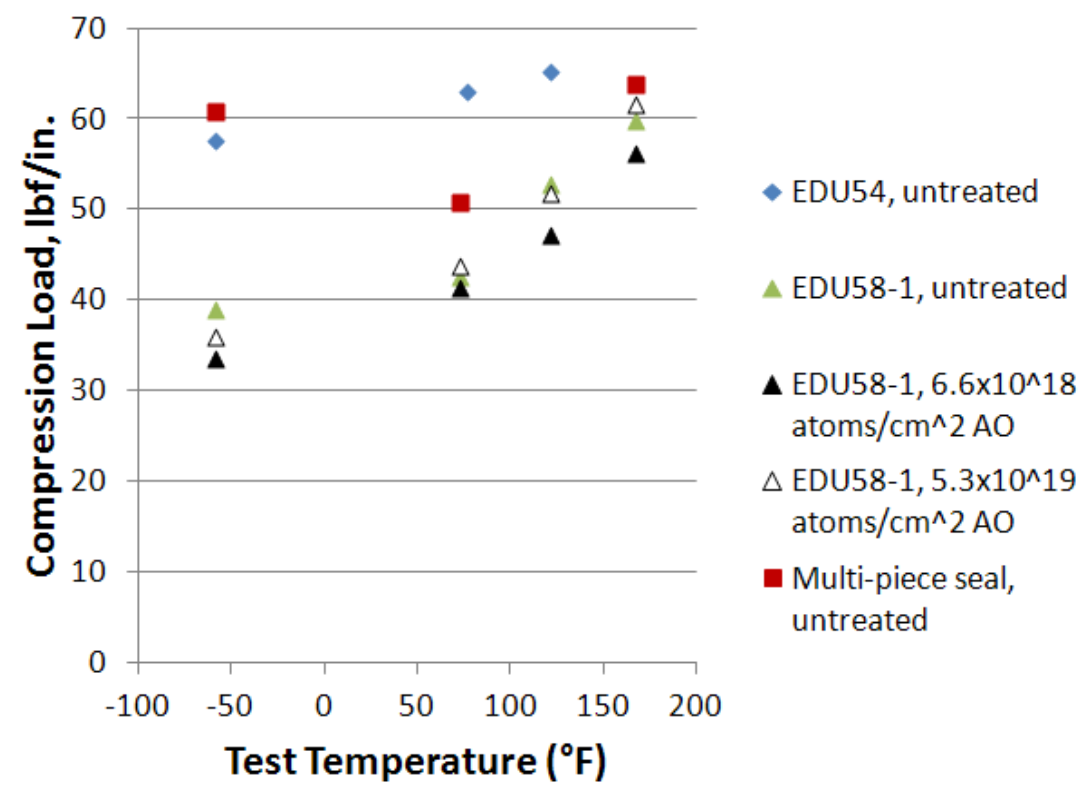

Figure 9.-Compression loads measured for candidate seal designs in the seal-on-flange mating configuration across a range of temperatures.

Several observations can be made from this figure:

- Loads measured for the multi-piece seal were comparable to those measured for the Gask-Oseals.

- For all of the Gask-O-seals that were tested, the force required to compress the seals increased with test temperature. However, this was not true for the multi-piece seal design as the load measured at $73{ }^{\circ} \mathrm{F}$ was less than those measured at -58 and $167^{\circ} \mathrm{F}$.

- EDU58-1 seals pre-treated with AO had comparable compression loads as those that were not treated.

- In all cases, the measured compression loads were below the threshold of $70 \mathrm{lb}_{\mathrm{f}}$ per in. of seal.

Figure 10 compares the compression loads measured for the EDU54 (Ref. 4) Gask-O-seals and multipiece seals (Ref. 14) in the seal-on-seal mating configuration from -58 to $167^{\circ} \mathrm{F}\left(-50\right.$ to $\left.75^{\circ} \mathrm{C}\right)$. As with Figure 9, the loads were measured from the first load cycle for these two seal designs. Several observations can be made:

- Compression loads for both designs were lower for seal-on-seal mating than for seal-on-flange mating. This was observed by both Smith (Ref. 4) and Oravec (Ref. 14) and was attributed to differences in boundary conditions at the mating interface. During seal-on-flange mating the seal interacts with a metal surface, and friction with that surface inhibits the seal from expanding in the radial direction. However, during seal-on-seal mating the two seal bulbs are able to spread laterally more easily thereby reducing compression loads.

- The multi-piece seals exhibited higher compression loads than the EDU54 seals did when tested under seal-on-seal conditions. This was in contrast with the seal-on-flange configuration in which the two seal designs exhibited similar compression loads.

- Compression loads for both designs were well below the $70 \mathrm{lb}_{\mathrm{f}}$ per in. requirement. 


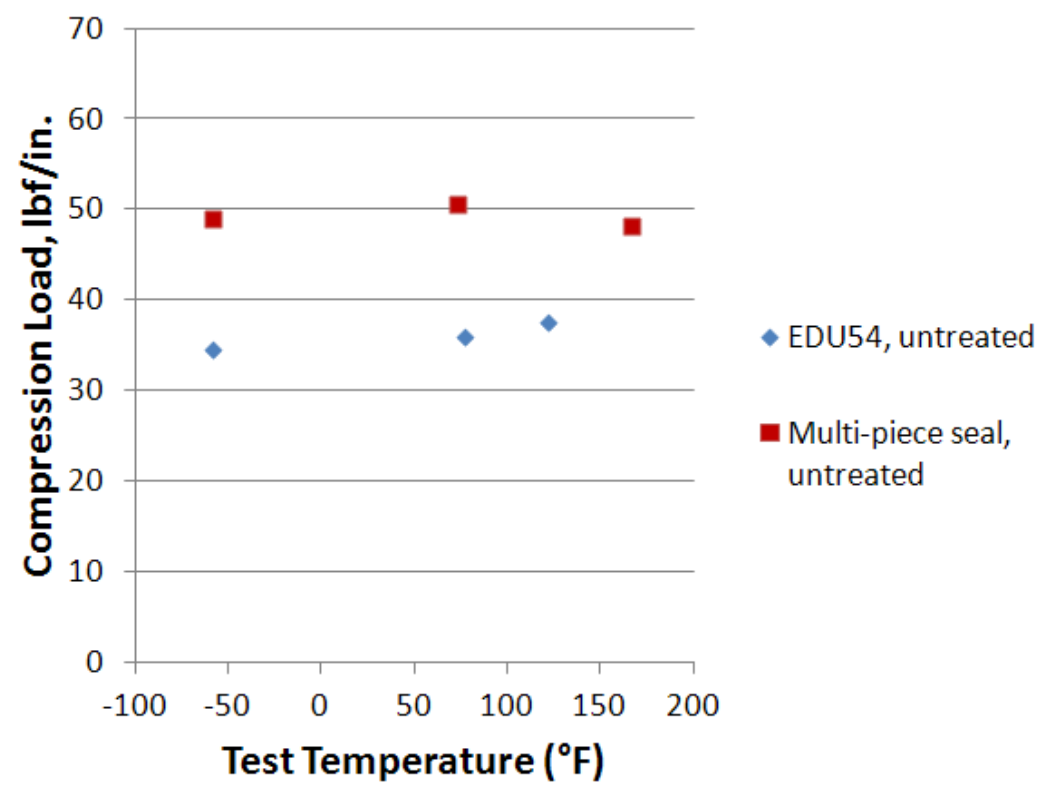

Figure 10.-Compression loads measured for candidate seal designs in the seal-on-seal mating configuration across a range of temperatures.

\section{Adhesion Loads}

\section{Untreated Seals}

As noted previously, seal adhesion loads have been shown to be quite high for untreated seals. Because of this, several studies have been conducted to assess the effects of AO pretreatment on seal adhesion loads (Refs. 9 and 15). Figure 11, Figure 12, and Figure 13 compare projected adhesion loads for EDU58 Gask-O-seals (Refs. 5 and 9) and multi-piece seals (Ref. 15) in an as-received, untreated state for dwell periods from 1 to $15 \mathrm{hr}$. The values plotted in these figures are extrapolated adhesion loads for 50 -in. diameter versions of each seal design based on adhesion loads measured for subscale seals of various diameters. Note that both seal bulbs are considered in these values. These results are presented for both mating configurations, seal-on-flange (SOF) and seal-on-seal (SOS), at $-58,73$, and $167^{\circ} \mathrm{F}(-50,23$, and $\left.75^{\circ} \mathrm{C}\right)$.

Temperature had the greatest impact on seal adhesion loads. The projected adhesion loads for each seal design were highest at $-58^{\circ} \mathrm{F}\left(-50^{\circ} \mathrm{C}\right)$. This has been attributed to an increase in the surface energy of the material as the temperature decreases (Ref. 5). Projected adhesion loads at room temperature $\left(73^{\circ} \mathrm{F}\right.$ $\left(23^{\circ} \mathrm{C}\right)$ ) were lower than those at $-58^{\circ} \mathrm{F}\left(-50^{\circ} \mathrm{C}\right)$ for all of the seal designs (Figure 12). Although the projected adhesion loads were still fairly high at room temperature, loads for the EDU58-1, EDU58-2, and EDU58-3 seals in the seal-on-flange configuration were all below the $200 \mathrm{lb}_{\mathrm{f}}$ threshold. At $167{ }^{\circ} \mathrm{F}$ $\left(75^{\circ} \mathrm{C}\right)$, no adhesion was measured for the EDU58 seals, continuing the trend of decreasing adhesion loads with increasing temperatures. However, these results were for a dwell period of only $15 \mathrm{hr}$, and additional testing is warranted for longer dwell periods before an untreated seal would be considered for the docking seal application.

Seal bulb height also affected adhesion loads. For the EDU58 family of seal designs, the projected adhesion load increased with seal bulb height. As noted previously, the EDU58-1 seals had the shortest front seal bulbs, and the EDU58-4 seals had the tallest. As such, the EDU58-1 seals exhibited the lowest projected adhesion loads, and the EDU58-4 seals had the highest projected loads. This was expected since taller seal bulbs project a larger contact area on the mating surface when fully compressed. 
The multi-piece seals exhibited comparable adhesion loads for seal-on-flange and seal-on-seal mating at the dwell times evaluated. In all cases, the projected adhesion loads exceeded the $200 \mathrm{lb}_{\mathrm{f}}$ threshold even for these short dwell times. During an actual mission in which the seals could remain docked for much longer periods of time (e.g., months), adhesion loads would be expected to increase. Interestingly, loads for the multi-piece seals at $167^{\circ} \mathrm{F}$ were comparable to those at room temperature for the dwell periods evaluated. This is in contrast with the EDU58 seals which exhibited decreased adhesion loads at $167^{\circ} \mathrm{F}$.

$-58 \operatorname{deg} F(-50 \operatorname{deg} \mathrm{C})$

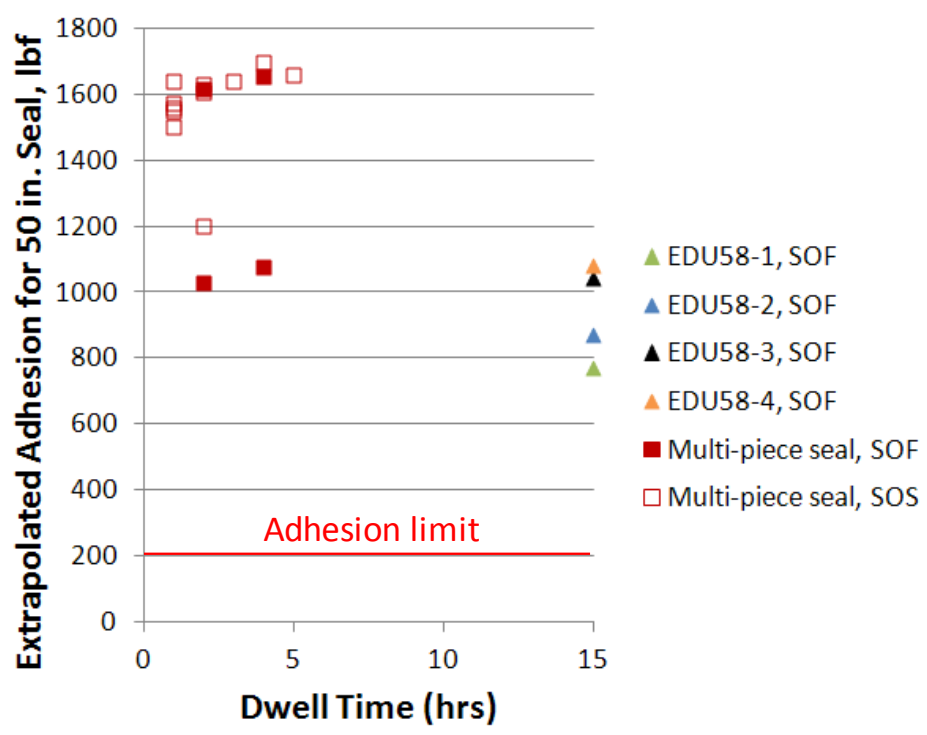

Figure 11.-Extrapolated adhesion loads for 50 in. diameter versions of candidate seal designs based on measured adhesion for untreated subscale seals in the SOF and SOS mating configurations for various dwell times at $-58^{\circ} \mathrm{F}\left(-50^{\circ} \mathrm{C}\right)$.

$73 \operatorname{deg} F(23 \operatorname{deg} C)$

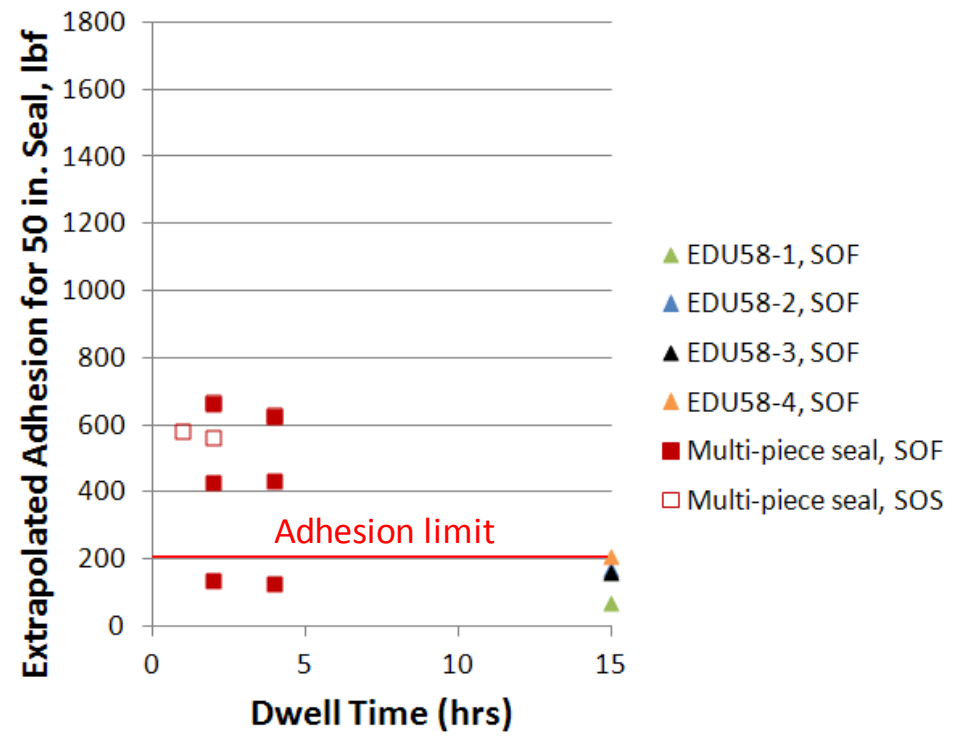

Figure 12.-Extrapolated adhesion loads for 50 in. diameter versions of candidate seal designs based on measured adhesion for untreated subscale seals in the SOF and SOS mating configurations for various dwell times at $73^{\circ} \mathrm{F}\left(23^{\circ} \mathrm{C}\right)$. 
$167 \operatorname{deg} F(75 \operatorname{deg} C)$

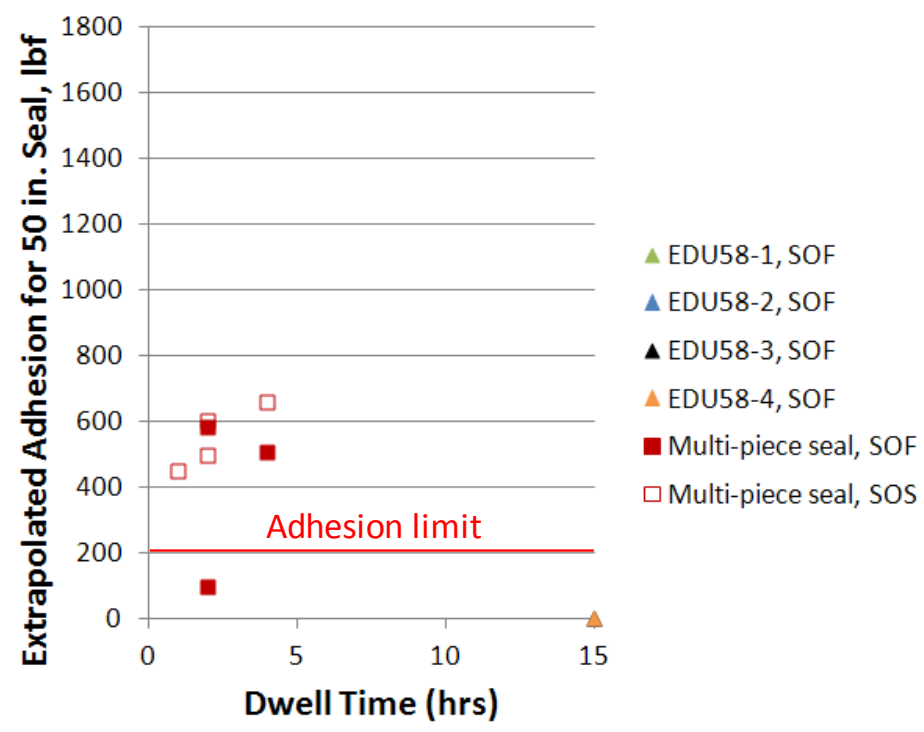

Figure 13.-Extrapolated adhesion loads for 50 in. diameter versions of candidate seal designs based on measured adhesion for untreated subscale seals in the SOF and SOS mating configurations for various dwell times at $167^{\circ} \mathrm{F}\left(75^{\circ} \mathrm{C}\right)$. (Note: All data points for EDU58 seals are $0 \mathrm{lb}_{\mathrm{f}}$ at $15 \mathrm{hr}$.)

In general, projected adhesion loads for the multi-piece seals were higher than those for the EDU58 seals. Factors contributing to this included the width and shape of the seal bulbs. The wider, flatter bulbs of the multi-piece seals increased their contact surface area, whereas the narrower, more rounded shape of the EDU58 seals allowed them to separate from the opposing surface more easily. Overall, projected adhesion loads for the untreated seals were higher than the adhesion load limit. Based on this, some form of adhesion reduction treatment is recommended to ensure that the seals satisfy the adhesion load requirement.

\section{AO Pretreated Seals}

Figure 14, Figure 15, and Figure 16 compare projected adhesion loads for EDU58 Gask-O-seals (Ref. 9) and multi-piece seals (Refs. 15 and 16) for various dwell periods and levels of AO pretreatment. These results are presented for both mating configurations, SOF and SOS, at $-58,73$, and $167^{\circ} \mathrm{F}(-50$, 23 , and $75^{\circ} \mathrm{C}$ ).

At all three test temperatures, the projected adhesion loads for the AO pretreated EDU58 and multipiece seals were considerably less than those in an as-received, untreated state even after longer dwell periods. This is consistent with previous studies showing that AO pretreated seals had significantly lower adhesion loads (Refs. 9 and 15). The only test case in which the projected adhesion load exceeded the $200 \mathrm{lb}_{\mathrm{f}}$ limit was for a multi-piece seal pretreated to an AO fluence of $1.5 \times 10^{20}$ atoms $/ \mathrm{cm}^{2}$ and compressed for $624 \mathrm{hr}\left(26\right.$ days) at $-58^{\circ} \mathrm{F}\left(-50^{\circ} \mathrm{C}\right)$ (Figure 14). These findings indicate a need to limit dwell times at the coldest temperatures prior to undocking or conversely the need to heat the interface after extended docking periods prior to undocking. All other cases evaluated for the EDU58 and multipiece seals exhibited projected adhesion loads less than the $200 \mathrm{lb}_{\mathrm{f}}$ limit. 
$-58 \operatorname{deg} F(-50 \operatorname{deg} C)$

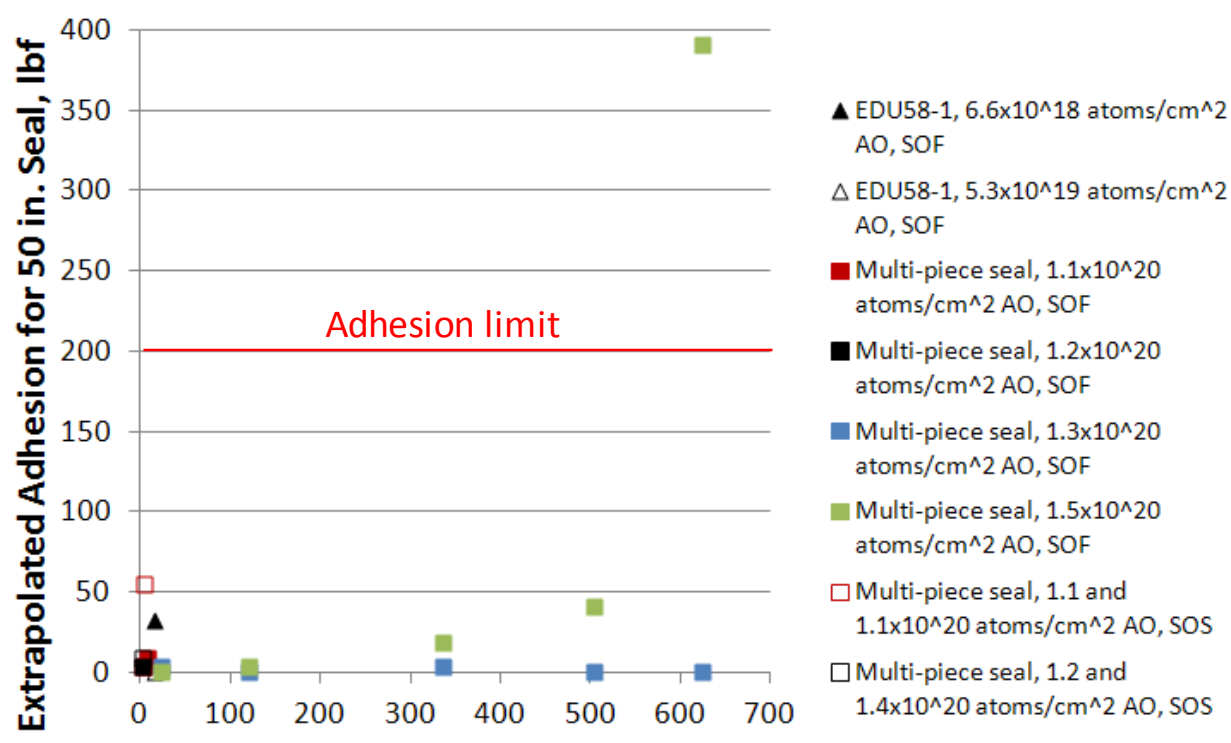

Dwell Time (hrs)

Figure 14.-Extrapolated adhesion loads for 50 in. diameter versions of candidate seal designs based on measured adhesion for $A O$ pretreated subscale seals in the SOF and SOS mating configurations for various dwell times at $-58^{\circ} \mathrm{F}\left(-50^{\circ} \mathrm{C}\right)$.

\section{$73 \operatorname{deg} F(23 \operatorname{deg} C)$}

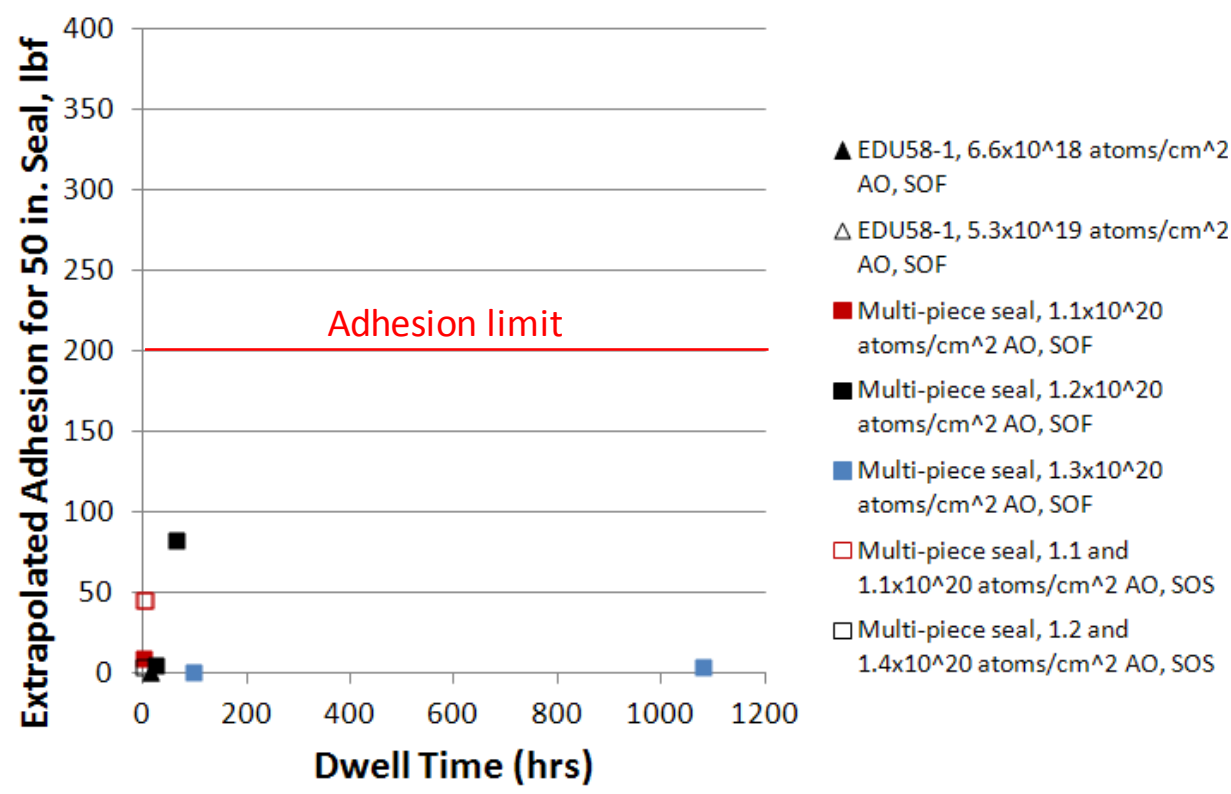

Figure 15.-Extrapolated adhesion loads for 50 in. diameter versions of candidate seal designs based on measured adhesion for $A O$ pretreated subscale seals in the SOF and SOS mating configurations for various dwell times at $73^{\circ} \mathrm{F}\left(23^{\circ} \mathrm{C}\right)$. 
$167 \operatorname{deg} F(75 \operatorname{deg} C)$

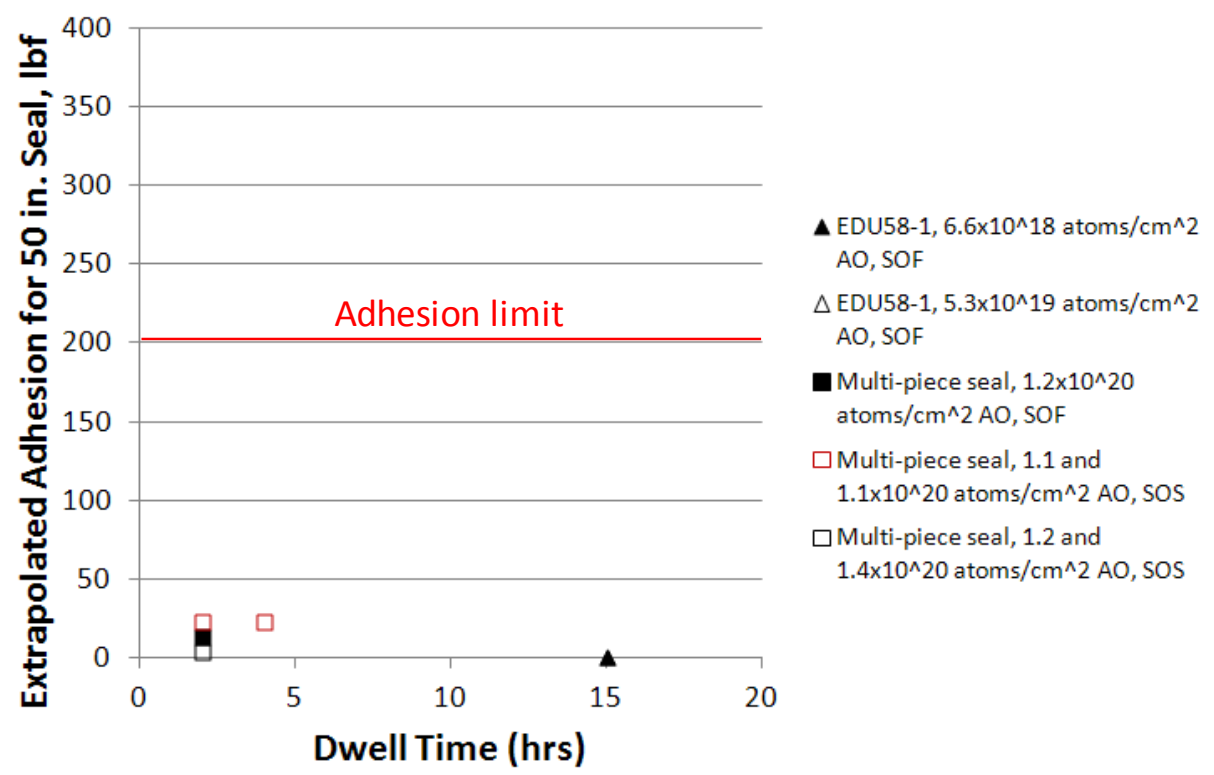

Figure 16.-Extrapolated adhesion loads for 50 in. diameter versions of candidate seal designs based on measured adhesion for $\mathrm{AO}$ pretreated subscale seals in the SOF and SOS mating configurations for various dwell times at $167^{\circ} \mathrm{F}\left(75^{\circ} \mathrm{C}\right)$.

\section{Other Considerations}

In addition to the performance assessments noted above, several other parameters can be used to evaluate and compare the candidate seal designs.

\section{Part Count}

Full-scale, 50-in. diameter versions of each of the candidate seal designs would likely use a comparable number of fasteners to secure them to the docking system tunnel. However, the seal designs themselves would be composed of different quantities of parts. One of the advantages of the Gask-O-seal design is that it can be fabricated in a single piece with the seal bulbs molded directly into the metal retainer. This allows the entire seal to be installed directly onto the tunnel as a single part. However, the multi-piece seal is composed of separate elements that are combined together to form the sealing system. The elastomer seal element would typically be molded as a single piece, while the separate metal retainer could be made as a single piece or in multiple segments. Thus, from a part count perspective, the candidate Gask-O-seal designs have an advantage over the multi-piece seal design.

\section{Installation and Interaction with Docking System Tunnel}

As noted earlier, Gask-O-seals would be installed directly on the top of a docking system tunnel without having to be installed in a separate groove whereas the multi-piece seal would likely need a groove in the tunnel surface. The amount of compression on the Gask-O-seal bulbs is controlled by the depth of the seal grooves in the metal retainer (Figure 4), and the load path through the interface goes directly through the seal retainer after docking (Figure 2(b)). For the multi-piece seals, though, the amount of compression on the seal bulbs is controlled by the depth of the groove in the tunnel (Figure 6). The height of the retainer is less than the depth of the groove so it does not become part of the load path 
after docking. This results in lower retainer stresses for the multi-piece seals since they are not subjected to the entire spectrum of docking loads.

\section{Mating Configuration}

One of the reasons that there is less seal-on-seal performance data published for the Gask-O-seal designs is that those types of designs are less amenable to seal-on-seal mating. Given the same flange width on the top of the docking system tunnel in which to fit the seal, candidate Gask-O-seal designs have narrower seal bulbs than comparable multi-piece seals due to the nature of the Gask-O-seal configuration (Figure 4). Because the seal bulbs are molded into the retainer, material must be left on either side of the bulbs to form the seal grooves. This limits the width of the seal grooves. Also, void space must be left on either side of the seal bulbs to allow them to spread out as they are compressed. These features result in narrower seal bulbs. In contrast, the bulb width for the multi-piece seal design is limited only by the width of the seal groove in the tunnel and the retainer installed between the seal bulbs (Figure 6). This configuration allows wider bulbs to be used which increases the seal's ability to accommodate larger tunnel-to-tunnel offsets and form an effective seal during seal-on-seal mating.

\section{Cost}

While the Gask-O-seal has an advantage over the multi-piece seal from a part count perspective in that the seal and retainer are integral, this feature also makes the Gask-O-seals more expensive. For seal-onseal applications, greater control on the exact placement of the seal bulbs in their grooves is necessary in order to tolerate large tunnel-to-tunnel misalignments. Precision fixturing is required between the seal retainer and mold hardware to achieve accurate bulb positioning. This can prove challenging during seal fabrication resulting in greater part rejection and increased part costs. In contrast, the retainer for the multi-piece seals is not integrally molded thereby eliminating the need for precision fixturing during the molding process, increasing yield, and reducing fabrication costs.

The retainer for the multi-piece seal design can be fabricated as a continuous ring for precise centering in the seal groove or in a multi-piece configuration. In applications considered to-date, the wider seal bulbs for this design allowed the multi-piece retainer approach to be pursued. For a 50 in. diameter seal, six arc segments nominally 26 in. in length would be less expensive to fabricate than the single-piece retainer that would be required for a Gask-O-seal of that size.

\section{Retainer Material Strength}

Another advantage for the multi-piece seal design is that the processing steps for the elastomer and retainer elements can optimized for their unique purposes. For instance, elastomer molding requires cure cycles at elevated temperatures to achieve low outgassing properties. When performed on a Gask-O-seal, these processes can reduce the yield strength of the integral aluminum retainer thereby limiting the loads under which the seals can operate. However, decoupling the elastomer and retainer elements in the multipiece seal design overcomes this issue as each element is processed separately.

\section{Performance Assessments and Comparisons}

Table I summarizes the performance assessments and comparisons that were made between the candidate seal designs. This includes the five specific types of Gask-O-seals (EDU54, EDU58-1, EDU582, EDU58-3, and EDU58-4) each of which had a different cross section. In the table, boxes that are marked in green indicate requirements that a specific seal design met or had a relative strength, while red boxes indicate that the seal design did not meet the requirement or had a relative weakness. 


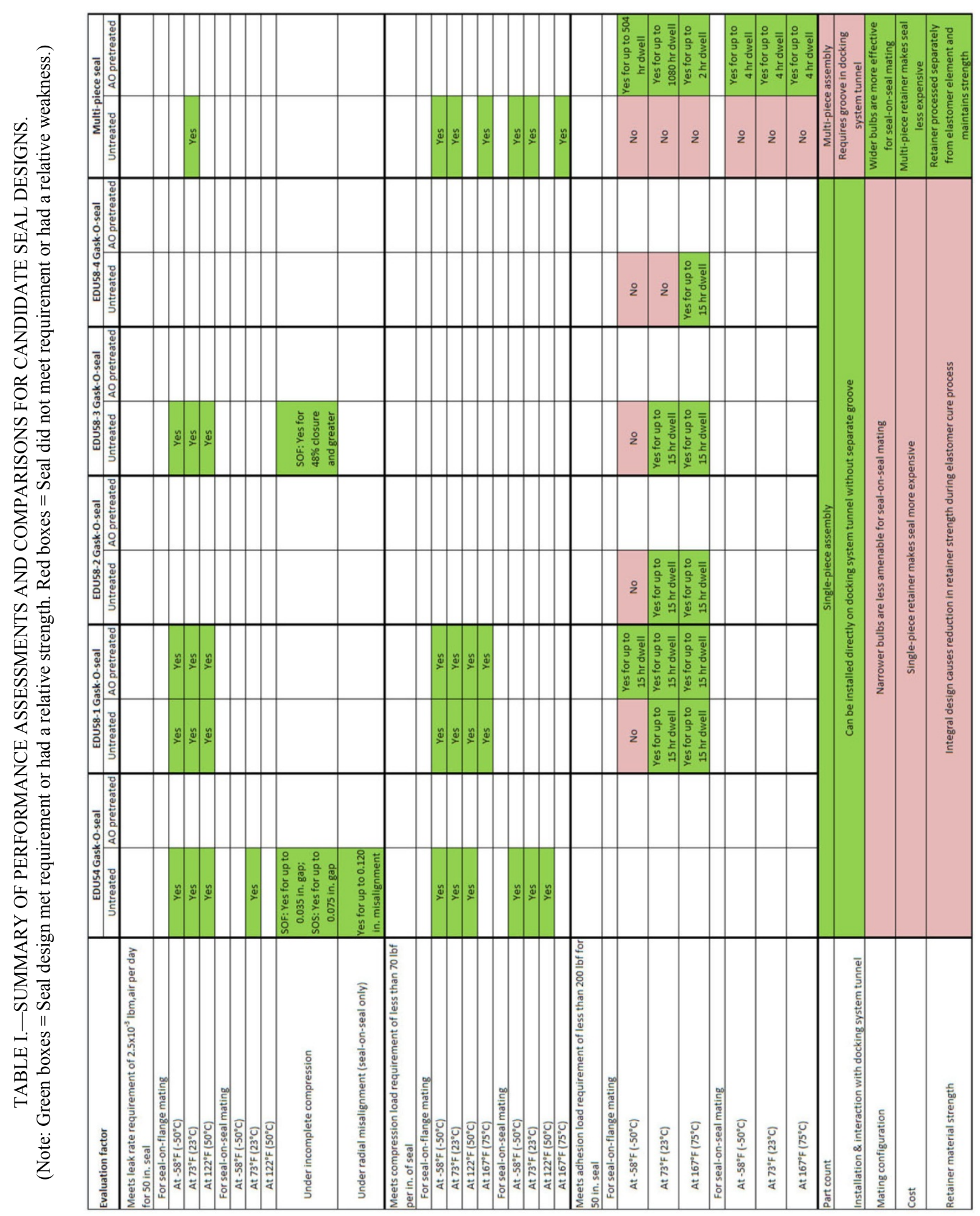




\section{Summary and Conclusions}

NASA is developing advanced, space-rated vacuum seals for future docking systems to seal the interfaces between mated vehicles and structures for missions to LEO and deep space. Two main types of seal designs were identified for this application: Gask-O-seals and multi-piece seals. Both types of seals had a pair of seal bulbs to satisfy the redundancy requirement. Based on the performance assessments and comparisons described above, the following conclusions and observations were made:

1. Several of the Gask-O-seal designs (EDU54, EDU58-1, and EDU58-3) satisfied the leak rate requirement when fully compressed in the seal-on-flange configuration at $-58,73$, and $122{ }^{\circ} \mathrm{F}$ $\left(-50,23\right.$, and $\left.50^{\circ} \mathrm{C}\right)$. The multi-piece seal design also met the leak rate requirement under these conditions, but published data was only available at room temperature.

2. Both the EDU54 and EDU58-3 seal designs were shown to be tolerant of incomplete compression and able to satisfy the leak rate requirement under those conditions.

3. The EDU54 Gask-O-seals met the leak rate requirement when fully compressed at room temperature in the seal-on-seal configuration. This seal design was also able to satisfy the leak rate requirement when misaligned radially by as much as $0.120 \mathrm{in}$.

4. The EDU54 and EDU58-1 Gask-O-seals and the multi-piece seals all met the compression load requirement in the seal-on-flange configuration, and the EDU54 and multi-piece seals met the requirement in the seal-on-seal configuration.

5. Higher than desired adhesion loads were projected for as-received, untreated, full-scale versions of the candidate seal designs. Based on this, some form of adhesion reduction treatment is required to ensure that the seals satisfy the adhesion load requirement.

6. Projected adhesion loads for AO pretreated EDU58 and multi-piece seals were considerably less than those tested in an as-received, untreated state even after longer dwell periods. AO pretreated multi-piece seals satisfied the adhesion requirement after dwell periods as long as 45 days at room temperature (the longest test performed to-date).

7. From a part count perspective, the single-piece Gask-O-seals would have an advantage over the multi-piece seal design. However, the large, single-piece retainer ring required for the Gask-Oseals and other molding considerations for seal-on-seal applications would likely make them more expensive.

8. Gask-O-seals can be installed directly on the top of a docking system tunnel whereas multi-piece seals require a separate groove in the tunnel surface for installation.

9. The wider seal bulbs of the multi-piece seal design make them more effective for seal-on-seal mating than the Gask-O-seals.

Based on these observations, designers of future docking systems and other habitable volumes can select the seal design best-suited for their particular application.

\section{References}

1. Dunlap, P.H., Daniels, C.C., Wasowski, J.L., Garafolo, N.G., Penney, N., and Steinetz, B.M., "Pressure Decay Testing Methodology for Quantifying Leak Rates of Full-Scale Docking System Seals,” NASA/TM-2010-216244, AIAA-2009-5319, April 2010.

2. Dunlap, P.H., Daniels, C.C., Steinetz, B.M., Erker, A.H., Robbie, M.G., Wasowski, J.L., Drlik, G.J., Tong, M.T., and Penney, N., "Full-Scale System for Quantifying Leakage of Docking System Seals for Space Applications," NASA/TM-2007-215024, AIAA-2007-5742, October 2007.

3. "C-1 Common Berthing Mechanism System Brief," JSC-36333 Vol. 2, 15 April 2005.

4. Smith, I.M., Daniels, C.C., Dunlap, P.H., and Steinetz, B.M., "Performance of Sub-scale Docking Seals under Simulated Temperature Conditions," AIAA-2008-4713, July 2008. 
5. Bastrzyk, M.B. and Daniels, C.C., "The Mechanical Performance of Subscale Candidate Elastomer Docking Seals," AIAA-2010-3129, April 2010.

6. Wasowski, J.L., Penney, N., Garafolo, N.G., and Daniels, C.C., "Leak Rates of a Candidate Main Interface Seal at Selected Temperatures," AIAA-2009-5320, August 2009.

7. Daniels, C.C., de Groh III, H., Dunlap, P.H., Finkbeiner, J.R., Steinetz, B.M., Bastrzyk, M.B., Oswald, J.J., Banks, B.A., Dever, J.A., Miller, S.K., and Waters, D.L., "Characteristics of Elastomer Seals Exposed to Space Environments," NASA/TM-2008-215005, AIAA-2007-5741, January 2008.

8. de Groh III, H.C., Miller, S., Smith, I.M., Daniels, C.C., and Steinetz, B.M., "Adhesion of Silicone Elastomer Seals for NASA's Crew Exploration Vehicle,” AIAA-2008-4625, July 2008.

9. Garafolo, N.G., Bastrzyk, M.B., and Daniels, C.C., "The Effects of Atomic Oxygen on the Sealing and Mechanical Performance of an Elastomer Seal," AIAA-2010-1440, January 2010.

10. Panickar, M.B., Wasowski, J.L., and Daniels, C.C., "Adhesion of an Elastomer Seal to Metal and its Mitigation with Atomic Oxygen Pretreatment," AIAA-2011-0426, January 2011.

11. Banks, B., Rutledge, S., Sechkar, E., Stueber, T., Snyder, A., de Groh, K., Haytas, C., and Brinker, D., "Issues and Effects of Atomic Oxygen Interactions With Silicone Contamination on Spacecraft in Low Earth Orbit," NASA/TM-2000-210056, May 2000.

12. Banks, B.A., de Groh, K.K., Rutledge, S.K., and Haytas, C.A., "Consequences of Atomic Oxygen Interaction With Silicone and Silicone Contamination on Surfaces in Low Earth Orbit," NASA/TM1999-209179, May 1999.

13. Garafolo, N.G. and Daniels, C.C., "An Experimental Investigation of Leak Rate Performance of a Subscale Candidate Elastomer Docking Space Seal,” AIAA-2010-6907, July 2010.

14. Oravec, H.A., Panickar, M.B., Wasowski, J.L., and Daniels, C.C., "Influence of Elastomer Compound and Test Temperature on the Compression Force of Candidate Space Seals: A Preliminary Study," AIAA-2011-5709, August 2011.

15. Oravec, H.A., Wasowski, J.L., and Daniels, C.C., "The Effect of Temperature and Dwell on the Adhesion Force of Silicone Elastomer Seals," AIAA-2012-0803, January 2012.

16. Dunlap, P.H., Martin, R.E., Garafolo, N.G., Oravec, H.A., and Steinetz, B.M., "Durability Testing of Docking System Seals for Space Applications," AIAA-2011-5710, August 2011. 



\begin{tabular}{|c|c|c|}
\hline \multicolumn{2}{|c|}{ REPORT DOCUMENTATION PAGE } & $\begin{array}{l}\text { Form Approved } \\
\text { OMB No. 0704-0188 }\end{array}$ \\
\hline \multicolumn{3}{|c|}{ 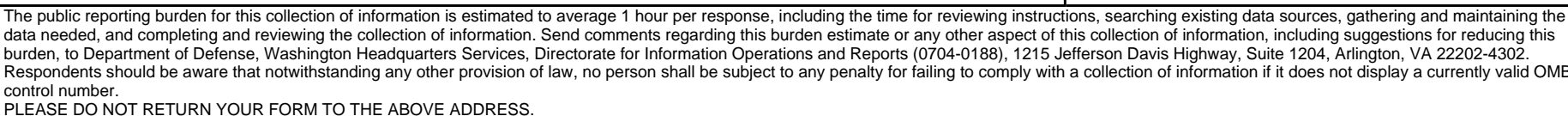 } \\
\hline $\begin{array}{l}\text { 1. REPORT DATE (DD-MM-YYYY) } \\
01-09-2012\end{array}$ & $\begin{array}{l}\text { 2. REPORT TYPE } \\
\text { Technical Memorandum }\end{array}$ & 3. DATES COVERED (From - To) \\
\hline \multirow{3}{*}{\multicolumn{2}{|c|}{$\begin{array}{l}\text { 4. TITLE AND SUBTITLE } \\
\text { A Comparison of Candidate Seal Designs for Future Docking Systems }\end{array}$}} & 5a. CONTRACT NUMBER \\
\hline & & 5b. GRANT NUMBER \\
\hline & & 5c. PROGRAM ELEMENT NUMBER \\
\hline \multirow{3}{*}{\multicolumn{2}{|c|}{$\begin{array}{l}\text { 6. AUTHOR(S) } \\
\text { Dunlap, Patrick, H., Jr.; Steinetz, Bruce, M. }\end{array}$}} & 5d. PROJECT NUMBER \\
\hline & & 5e. TASK NUMBER \\
\hline & & $\begin{array}{l}\text { 5f. WORK UNIT NUMBER } \\
\text { WBS 401769.06.02.01.10 }\end{array}$ \\
\hline \multicolumn{2}{|c|}{$\begin{array}{l}\text { 7. PERFORMING ORGANIZATION NAME(S) AND ADDRESS(ES) } \\
\text { National Aeronautics and Space Administration } \\
\text { John H. Glenn Research Center at Lewis Field } \\
\text { Cleveland, Ohio 44135-3191 }\end{array}$} & $\begin{array}{l}\text { 8. PERFORMING ORGANIZATION } \\
\text { REPORT NUMBER } \\
\text { E-18433 }\end{array}$ \\
\hline \multirow{2}{*}{\multicolumn{2}{|c|}{$\begin{array}{l}\text { 9. SPONSORING/MONITORING AGENCY NAME(S) AND ADDRESS(ES) } \\
\text { National Aeronautics and Space Administration } \\
\text { Washington, DC 20546-0001 }\end{array}$}} & $\begin{array}{l}\text { 10. SPONSORING/MONITOR'S } \\
\text { ACRONYM(S) } \\
\text { NASA }\end{array}$ \\
\hline & & $\begin{array}{l}\text { 11. SPONSORING/MONITORING } \\
\text { REPORT NUMBER } \\
\text { NASA/TM-2012-217722 }\end{array}$ \\
\hline \multicolumn{3}{|c|}{$\begin{array}{l}\text { 12. DISTRIBUTIONIAVAILABILITY STATEMENT } \\
\text { Unclassified-Unlimited } \\
\text { Subject Category: } 37 \\
\text { Available electronically at http://www.sti.nasa.gov } \\
\text { This publication is available from the NASA Center for AeroSpace Information, 443-757-5802 }\end{array}$} \\
\hline
\end{tabular}

\section{SUPPLEMENTARY NOTES}

\section{ABSTRACT}

NASA is developing a new docking system to support future space exploration missions to low Earth orbit, the Moon, and other destinations. A key component of this system is the seal at the main docking interface which inhibits the loss of cabin air once docking is complete. Depending on the mission, the seal must be able to dock in either a seal-on-flange or seal-on-seal configuration. Seal-on-flange mating would occur when a docking system equipped with a seal docks to a system with a flat metal flange. This would occur when a vehicle docks to a node on the International Space Station. Seal-on-seal mating would occur when two docking systems equipped with seals dock to each other. Two types of seal designs were identified for this application: Gask-O-seals and multi-piece seals. Both types of seals had a pair of seal bulbs to satisfy the redundancy requirement. A series of performance assessments and comparisons were made between the candidate seal designs indicating that they meet the requirements for leak rate and compression and adhesion loads under a range of operating conditions. Other design factors such as part count, integration into the docking system tunnel, seal-on-seal mating, and cost were also considered leading to the selection of the multi-piece seal design for the new docking system. The results of this study can be used by designers of future docking systems and other habitable volumes to select the seal design best-suited for their particular application.

\section{SUBJECT TERMS}

Seals; Design; Leakage; Compression tests; Adhesion tests; Load tests; Docking

\begin{tabular}{|c|c|c|c|c|c|}
\hline \multicolumn{3}{|c|}{ 16. SECURITY CLASSIFICATION OF: } & \multirow{2}{*}{$\begin{array}{l}\text { 17. LIMITATION OF } \\
\text { ABSTRACT } \\
\text { UU }\end{array}$} & \multirow{2}{*}{$\begin{array}{l}\text { 18. NUMBER } \\
\text { OF } \\
\text { PAGES } \\
26\end{array}$} & \multirow{2}{*}{$\begin{array}{l}\text { 19a. NAME OF RESPONSIBLE PERSON } \\
\text { STI Help Desk (email:help@sti.nasa.gov) } \\
\text { 19b. TELEPHONE NUMBER (include area code) } \\
\text { 443-757-5802 }\end{array}$} \\
\hline $\begin{array}{l}\text { a. REPORT } \\
U\end{array}$ & $\begin{array}{l}\text { b. ABSTRACT } \\
\mathrm{U}\end{array}$ & $\begin{array}{l}\text { c. THIS } \\
\text { PAGE } \\
\text { U }\end{array}$ & & & \\
\hline
\end{tabular}



